\title{
Efecto de la sulfonación del estireno-éster acrílico sobre las propiedades de las membranas de intercambio protónico
}

\author{
Effect of the Sulfonation of Styrene-Acrylic Ester on the Properties of Proton \\ Exchange Membranes
}

\author{
Realpe-Jiménez Álvaro \\ Universidad de Cartagena \\ Facultad de Ingeniería \\ Correo:arealpe@unicartagena.edu.co \\ Maza-Puerta Yilmar \\ Universidad de Cartagena \\ Facultad de Ingeniería \\ Correo:ymazap@hotmail.com
}

\author{
Acevedo-Morantes María Teresa \\ Universidad de Cartagena \\ Facultad de Ingeniería \\ Correo:macevedo@unicartagena.edu.co \\ Herrera-Barros Adriana \\ Universidad de Cartagena \\ Facultad de Ingeniería \\ Correo:aherrerab2@unicartagena.edu.co
}

Información del artículo: recibido: febrero de 2015, aceptado: mayo de 2015

\section{Resumen}

En este trabajo se estudió el efecto de la sulfonación de estireno-éster acrílico y adición de nanopartículas de dióxido de titanio sobre las membranas de intercambio protónico. Se evaluó la caracterización fisicoquímica de las membranas, tales como: la capacidad de absorción de agua, su capacidad de intercambio iónico, las propiedades mecánicas de tracción/deformación y los grupos químicos funcionales presentes en la estructura de las membranas mediante análisis FTIR. La absorción de agua incrementa con el aumento del tiempo de reacción de la sulfonación y llega hasta $60.9 \%$ después de 8 horas de sulfonación; mientras la capacidad de intercambio iónico de las membranas cargada-sulfonada también aumenta con el tiempo de la reacción de sulfonación y con aumento de la carga de $\mathrm{TiO}_{2}$, alcanzando un valor de 0.39 miliequivalente/gramo para 8 horas y cargada con $4 \%$ de $\mathrm{TiO}_{2}$. Se observó que la elasticidad de las membranas sintetizadas se incrementó con el crecimiento del tiempo de reacción y disminuyó con la adición de la carga. Este conjunto de propiedades fisicoquímica permite considerar la membrana con alto potencial de aplicación en el área de las celdas de combustible.

\section{Descriptores:}

- membrana de intercambio protónico

- estireno-éster acrílico

- sulfonación

- nanopartículas

- dióxido de titanio 


\begin{abstract}
In this work was studied the effect of sulfonation of styrene-acrylic ester and of titanium dioxide nanoparticles on the proton exchange membranes. It was evaluated the physicochemical characterization of membranes, such as, the water uptake capacity, ion exchange capacity, the mechanic properties of stress/strain, and the chemical functional groups present in the membrane structure by FTIR analysis. Water uptake increases with increasing the time of sulfonation reaction, reaching $60.9 \%$ after 8 hours of sulfonation; while, ion exchange capacity of loaded-sulfonated membrane increases with increasing the time of sulfonation reaction and with increasing the $\mathrm{TiO}_{2}$ load, reaching $0.39 \mathrm{meq} / \mathrm{g}$ for 8 hours and $4 \% \mathrm{TiO}_{2}$. It was observed that the elasticity of the synthesized membranes increases with increasing the time of sulfonation reaction, and it decreases with the addition of the $\mathrm{TiO}_{2}$ load. This physicochemical property set allows to consider the membrane with high potential of application in the fuel cells area.
\end{abstract}

\section{Introducción}

Hoy en día, la energía se ha convertido en uno de los asuntos con mayor interés a nivel mundial. En un mundo marcado por la dependencia energética, la búsqueda de producción y necesidad de suministro se convierten en premisas fundamentales a la hora de crear una política energética.

Con el fin de encontrar nuevas formas de energía limpia y renovable, además de reducir nuestra dependencia de los combustibles fósiles para evitar el calentamiento global, se estudian las celdas de combustible de membranas de intercambio protónico (PEM-FC), como una alternativa para el desarrollo de tecnologías sostenibles (Chen et al., 2013; Kim y Nam, 2013), debido a las ventajas que presenta su operación, incluida la mejora de la cinética electroquímica, la simplicidad en el manejo de subproductos (agua) y la recuperación de calor residual (Treekamol et al., 2014). Estos dispositivos producen energía eléctrica por conversión directa de energía química a través de una serie de reacciones electroquímicas de gases de alimentación (por ejemplo, hidrógeno) (Jiang et al., 2013; Zhang et al., 2012). Actualmente se exploran para una amplia gama de aplicaciones en energía estacionaria, de automoción y portátil.

La membrana de intercambio protónico (PEM), que es un componente fundamental de la PEMFC, actúa como un electrolito sólido que separa las reacciones electroquímicas que ocurren en el ánodo hacia el cátodo y viceversa (Dai et al., 2008; Park et al., 2012; Wang et al., 2012). Estas membranas deben ser buenas conductoras de protones, poseer buena resistencia mecánica, estabilidad dimensional y una larga vida útil (Seol et al., 2012). Las membranas de ácidos sulfónicos perfluorados tales como Nafion ${ }^{\circledR}$ se han utilizado ampliamente como PEM, debido a que muestran una conductividad protónica alta y buena estabilidad química. Sin embargo, existen inconvenientes como alta permeabilidad de metanol, baja temperatura de operación, mala adherencia entre la membrana y los electrodos y alto costo de fabricación, que reducen el rango de aplicaciones (Cozzi et al., 2014; Lin y Wag, 2013).

Por lo anterior, un gran número de polímeros aromáticos sulfonados y sus derivados, así como mezclas entre ellos, se han desarrollado como alternativas para sintetizar membranas de intercambio protónico (Liao et al., 2013). Jetsrisuparb y colaboradores (2013) prepararon membranas de intercambio protónico a partir del injerto de estireno sulfonado y co-monómeros de meta acrilonitrilo y acrilonitrilo en una matriz parcialmente fluorada, las cuales se evaluaron en una celda de combustible, donde presentaron buena estabilidad dimensional y resistencia mecánica al mostrar la membrana con estireno y acrilonitrilo, que exhibió mejores resultados. Suryani et al., (2012), prepararon una membrana de intercambio protónico a partir de polibenzimidazol unido químicamente a nanopartículas de sílice, con que mejoraron las propiedades mecánicas de la membrana e incrementaron su conductividad protónica. Como consecuencia, la membrana presentó un mejor rendimiento en una celda de combustible.

El objetivo del presente trabajo es sintetizar y caracterizar las propiedades físico-químicas de membranas de intercambio protónico obtenidas a partir de la resina estireno-éster acrílico mediante reacciones de sulfonación a diferentes tiempos y adición de carga inorgánica de nanopartículas de dióxido de titanio $\left(\mathrm{TiO}_{2}\right)$, en porcentajes de peso de 1 y $4 \%$, con el propósito de evaluar su capacidad de retención de agua, intercambio iónico, propiedades mecánicas y grupos químicos fun- 
cionales presentes en la estructura de la membrana, a través de espectroscopia de infrarrojo, con el fin de evaluar el uso potencial en aplicaciones de celdas de combustible.

\section{Materiales y métodos}

El copolímero empleado para el desarrollo de esta investigación fue estireno-éster acrílico (distribuido por la empresa RECOL, bajo el nombre de RECOL® CRYL). Las nanopartículas de dióxido de titanio se sintetizaron siguiendo la metodología reportada por Martínez y Reyes (2013) a partir de la reducción de una solución de isopropóxido de titanio IV $(5.0 \mathrm{mM})$ usando un extracto acuoso obtenido a partir de la planta herbácea hierba limón. Después de sintetizadas las nanopartículas, se sometieron a un tratamiento térmico de $550^{\circ} \mathrm{C}$ durante 3 horas, usando para esto una mufla de calcinación. En la preparación de las membranas se emplearon los reactivos anhídrido acético, ácido sulfúrico, ácido clorhídrico, hidróxido de sodio, estireno y metanol; la caracterización se reporta por Martínez y Reyes (2013).

Para la preparación de la membrana sin modificar (muestra SM), inicialmente se disolvieron $10 \mathrm{~g}$ de la resina en $40 \mathrm{ml}$ de agua destilada a $40^{\circ} \mathrm{C}$, bajo agitación magnética durante $5 \mathrm{~min}$. Luego se vertió esta solución en cajas Petri para la formación de las películas con un espesor promedio de $1.23 \mathrm{~mm}$. En el caso de la preparación de las membranas cargadas con nanopartículas de dióxido de titanio $\left(\mathrm{TiO}_{2}\right)$ (muestras C-1 y C-4), se procedió a adicionar las nanopartículas en la solución acuosa formada con la resina, hasta obtener proporciones de 1 y $4 \%$ p/p nanopartículas/resina.

El agente sulfonante se preparó a partir de una solución de sulfato de acetilo, la cual se obtuvo disolviendo $4.7 \mathrm{~mL}$ de anhídrido acético en $100 \mathrm{ml}$ de agua destilada, usando para esto un baño de hielo. A esta solución se le agregaron $2.7 \mathrm{~mL}$ de ácido sulfúrico y se dejó reaccionando durante 10 minutos. Para la preparación de las membranas sulfonadas, se disolvieron $10 \mathrm{~g}$ de la resina estireno-éster acrílico en $100 \mathrm{~mL}$ de agua destilada durante 15 minutos usando un balón de fondo plano, después se adicionó gota a gota la solución de agente sulfonante para llevar la reacción de sulfonación durante períodos de tiempo de 2, 3, 4, 5, y 8 horas (muestras S2, S3, S4, S5 y S8). Pasado el tiempo de sulfonación, se detuvo la reacción adicionando $100 \mathrm{~mL}$ de metanol, tras lo cual el polímero se filtró, secó y se disolvió en estireno para vertirse en cajas Petri, donde se evaporó el solvente y se formó la película.

Para obtener membranas sulfonadas y cargadas con nanopartículas de dióxido de titanio (muestras SC), se agregó la carga de nanopartículas (1 y 4 \% p/p) después del proceso de sulfonación de la resina y disolución en estireno, tal como se describió en el párrafo anterior. Posteriormente se dejó homogenizar la mezcla y se vertió en cajas Petri para la formación de las membranas (Realpe et al., 2014).

\section{Caracterización de las membranas}

\section{Capacidad de retención de agua}

Cada tipo de membrana se dividió en tres secciones de $2 \mathrm{~cm} \times 2 \mathrm{~cm}$, se secaron en un horno a $35^{\circ} \mathrm{C}$ por una hora para eliminar el exceso de humedad (Park et al., 2012), luego se determinó el peso en seco y se sumergió cada una en $50 \mathrm{ml}$ de agua destilada durante 24 horas. Pasado este tiempo cada muestra se extrajo, se removió el agua superficial con papel absorbente y se pesó la muestra húmeda (Shahi, 2007). La diferencia entre el peso húmedo y seco proporcionó la capacidad de retención de agua que se calculó mediante la siguiente ecuación (Wang et al., 2010)

$\%$ Retención $=\frac{\text { peso húmedo }- \text { peso seco }}{\text { peso seco }} \times 100$

Capacidad de intercambio iónico

Tres muestras de $2 \mathrm{~cm} \times 2 \mathrm{~cm}$ de cada membrana preparada se sumergieron durante 24 horas en una solución preparada al 1M con ácido clorhídrico. Pasado el tiempo, se extrajeron las muestras y se agregaron a una solución $1 \mathrm{M}$ de $\mathrm{NaCl}$ durante 24 horas. Finalmente se extrajeron las membranas y se titularon la soluciones con $0.01 \mathrm{M}$ de $\mathrm{NaOH}$. La capacidad de intercambio iónico se calculó mediante la siguiente ecuación

$\operatorname{IEC}\left(\frac{\text { mequiv }}{g}\right)=\frac{V_{\mathrm{NaOH}} \times M}{W}$

donde

$V \quad=$ volumen

$\mathrm{N}_{a} \mathrm{OH}=$ agregado para neutralizar la solución

$M \quad=$ concentración de $\mathrm{NaOH}$

$W \quad$ = peso de la muestra seca

Propiedades mecánicas

Las propiedades mecánicas de la membrana, como la resistencia a la tracción, esfuerzo y deformación se calcularon con una máquina universal de ensayos EZ-S de 
Shimadzu, a una velocidad constante de $250 \mathrm{~mm} / \mathrm{min}$, usando las normas NTC 942. El tamaño de la muestra empleada fue $5 \mathrm{~cm} \times 5 \mathrm{~cm}$ y espesor de aproximadamente $1.23 \mathrm{~mm}$.

\section{Espectroscopía de infrarrojo}

Se realizó un análisis de espectroscopía infrarroja de las membranas sin modificar, cargada, sulfonada $3 \mathrm{~h}$ y sulfonada $8 \mathrm{~h}$, para verificar el éxito de cada uno de los procesos de modificación. Para ello, se usó un espectrofotómetro de transformada de Fourier de referencia Nicolet 6700, en un rango de medición de longitud de onda de 4000 a $400 \mathrm{~cm}^{-1}$.

\section{Resultados y discusión}

\section{Capacidad de intercambio iónico y retención de agua}

Los resultados para las pruebas de retención de agua e intercambio iónico de todas las membranas sintetizadas se presentan en las figuras 1 y 2 , respectivamente. Todas las membranas preparadas presentaron mayores valores en propiedades de retención de agua e intercambio iónico en comparación con la membrana sin modificar. La retención de agua de $16.1 \%$ de la membrana sin modificar confirma su uso como auxiliar de impermeabilización, característica atribuida además de la naturaleza del material, por el contenido de sólidos presentes (50\% p/p) (Recol SAS, 2011).

Para una transferencia de protones óptima en la membrana, se requiere la presencia de agua durante la operación en una celda de combustible, de allí la importancia de tener membranas con alta capacidad de absorción de agua (Yu et al., 2013). La figura 1 muestra el aumento de la retención de agua con la adición de la carga en comparación con la membrana sin modificar, debido a la presencia del grupo inorgánico hidrofílico de $\mathrm{TiO}_{2}$ en la estructura polimérica (Mohammadi et al., 2012). También se observó una clara dependencia de esta propiedad con el tiempo de sulfonación, pasando de $21.8 \%$ para las membranas sulfonadas durante $2 \mathrm{~h}$ hasta $60.9 \%$ para las membranas sulfonadas por un período de tiempo de hasta $8 \mathrm{~h}$. Esto puede atribuirse a que, a mayor tiempo de sulfonación, se logró introducir una mayor cantidad de grupos sulfónicos en la cadena principal del polímero, lo cual permite exhibir una característica hidrofílica más favorable para la captación de agua (Bose et al., 2011; Méndez y Toscano, 2013).

La interacción sulfonación-carga disminuye ligeramente la retención de agua con el aumento en el por- centaje carga, esto puede ser producto del confinamiento que presentan las nanopartículas de $\mathrm{TiO}_{2}(18 \pm 6$ $\mathrm{nm}$ ) dentro de la resina, acompañado de los grupos sulfónicos adheridos a la cadena, lo que provoca una reducción del volumen libre que permite la captación de agua (Samberan et al., 2013). Resultados similares se muestran por Devrim et al. (2009), quienes reportan una reducción en la retención de agua al sulfonar y cargar con $\mathrm{TiO}_{2}$ una muestra de polisulfona, en comparación con los valores obtenidos para este mismo material solo sulfonado, bajo las mismas condiciones de sulfonación.

Por otra parte, la figura 2 muestra cómo la capacidad de intercambio iónico (IEC) se favorece por el tiempo sulfonación y, a su vez, por la adición de carga al polímero sulfonado, como consecuencia del aumento de los sitios activos que permiten la transferencia de protones. Esta transferencia de protones en una membrana de intercambio se presenta por medio de dos mecanismos simultáneos o con dominio de uno sobre el otro, el primero es el mecanismo de Grotthus, en el cual los protones saltan de un sitio donador $\mathrm{H}^{+}$hacia la molécula de agua más cercana para formar un complejo $\mathrm{H}_{3} \mathrm{O}^{+}$, el segundo es el mecanismo vehicular donde los protones se transfieren a través de los grupos hidroxilos (Mendez y Toscano, 2013).

Para el caso de las membranas solo cargadas a $1 \mathrm{y}$ $4 \%$ en peso de nanopartículas de $\mathrm{TiO}_{2}$ los valores de IEC son bajos ( 0.1 y $0.18 \mathrm{meq} / \mathrm{g}$, respectivamente) a pesar de presentar una alta captación de agua, esto se debe a la reducción del volumen libre dentro de la estructura, lo que dificulta el paso de los protones. El IEC aumenta con el tiempo de sulfonación y carga, como consecuencia de la presencia de los grupos sulfónicos que incrementan la densidad de grupos iónicos cargados negativamente por volumen de las membranas, lo que provoca valores más altos de IEC $(0.39 \mathrm{meq} / \mathrm{g}$ para

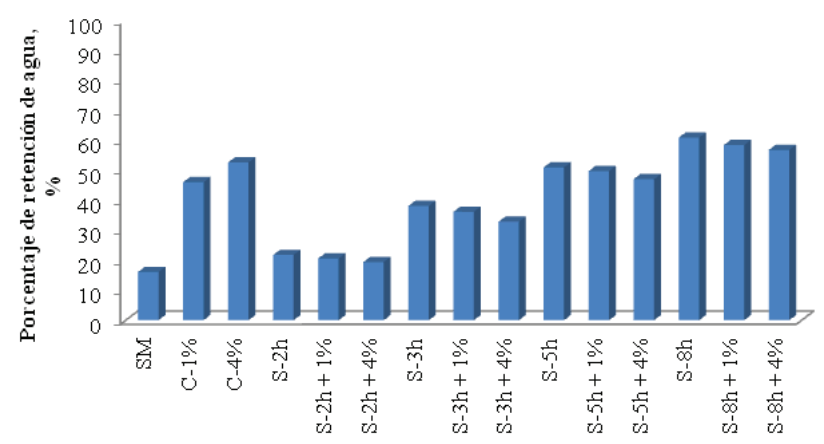

Figura 1. Capacidad de retención de agua. SM: membrana sin modificar, C-\%: membrana cargada al porcentaje indicado, S-: membrana sulfonada al tiempo indicado, S-\%: membrana sulfonada al tiempo y carga indicado 


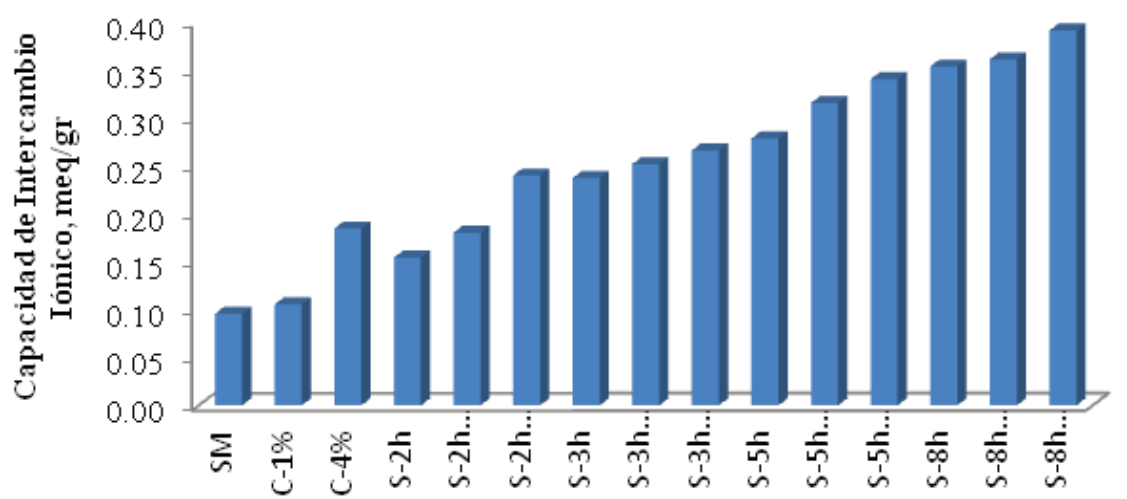

Figura 2. Capacidad de intercambio iónico. SM: membrana sin modificar, C-\%: membrana cargada al porcentaje indicado, S-: membrana sulfonada al tiempo indicado, S-\%: membrana sulfonada al tiempo y carga indicado

la membrana sulfonada $8 \mathrm{~h}$ y cargada $4 \%$ ) (Samberan $e t$ al., 2013). Resultados similares se presentaron por Méndez y Toscano (2013) para las mismas condiciones de sulfonación del material y un tiempo de $3 \mathrm{~h}$ con un valor de $0.24 \mathrm{meq} / \mathrm{g}$ y $0.27 \mathrm{meq} / \mathrm{g}$ para las membranas sulfonadas cargadas solo con $\mathrm{TiO}_{2}$.

\section{Propiedades mecánicas}

La resistencia mecánica de la membrana de intercambio protónico es un parámetro importante a la hora de su fabricación, debido a que permite una amplia gama de montaje bajo presión y evita la formación de arrugas, excluyendo las diferencias de grosor y la mala adherencia (Tsai et al., 2013). Además, los materiales que la conforman deben ser lo suficientemente fuertes como para manipularse durante el procesamiento.

También afectarán la durabilidad del funcionamiento de la celda, en la que son difíciles de evitar las tensiones térmicas inducidas, especialmente durante la operación de arranque/parada (Yuan et al., 2014). Para evaluar la influencia de la composición sobre las propiedades mecánicas de las membranas, se realizaron ensayos de tracción-deformación a cada una de las muestras sintetizadas y se compararon con valores obtenidos con una membrana comercial de Nafion NRE 211-10. Los resultados se presentan en las figuras 3 y 4 , donde se marca el comportamiento de estas propiedades para algunas de las muestras preparadas.

La figura 3 muestra como el tiempo de sulfonación mejora la resistencia mecánica de la membrana de 2.15 Mpa para la muestra sin modificar hasta $2.98 \mathrm{Mpa}$, para la muestra sulfonada $3 \mathrm{~h}$, producto de la unión de los grupos sulfónicos a la cadena del copolímero que le atribuye mayor resistencia mecánica (Kim et al., 2008). Además, las fuertes interacciones iónicas de los grupos sulfónicos aumentaron la rigidez de los enlaces entre las cadenas moleculares (Zhao y Yin, 2010). Para un mayor tiempo de sulfonación (8h) comienza una reducción de la resistencia a la tracción, por efecto de la gran retención de agua que presentan estas membranas, lo que provoca que actúe como plastificante dentro de la matriz polimérica.

Una buena resistencia mecánica mejorará la durabilidad de toda la membrana, y por ende la hace más factible para utilizarse como electrolito en una celda de combustible, con el fin de optimizar el rendimiento de la misma (Wang et al., 2013). La figura 4 muestra el efecto de la carga en las propiedades mecánicas de las muestras sintetizadas. Un aumento en el porcentaje de nanopartículas de $\mathrm{TiO}_{2}$ mejora la resistencia de la membrana, con un valor de $3.78 \mathrm{MPa}$ para la membrana sulfonada $3 \mathrm{~h}$ con $4 \%$ en peso de carga frente a $2.98 \mathrm{MPa}$ para la solo sulfonada $3 \mathrm{~h}$.

Por otra parte, las membranas solo cargadas a $1 \mathrm{y}$ $4 \%$ presentan los valores más bajos en los resultados del ensayo (0.8 y $1.17 \mathrm{MPa}$, respectivamente), esto es producto del alto porcentaje de retención de agua que presentan estas muestras, ya que produce un hinchamiento de la misma reduciendo su resistencia a la tracción. Resultados similares se obtuvieron en otros estudios donde la membrana operó sin problemas mecánicos en una celda de combustible. Yuan y colaborado-

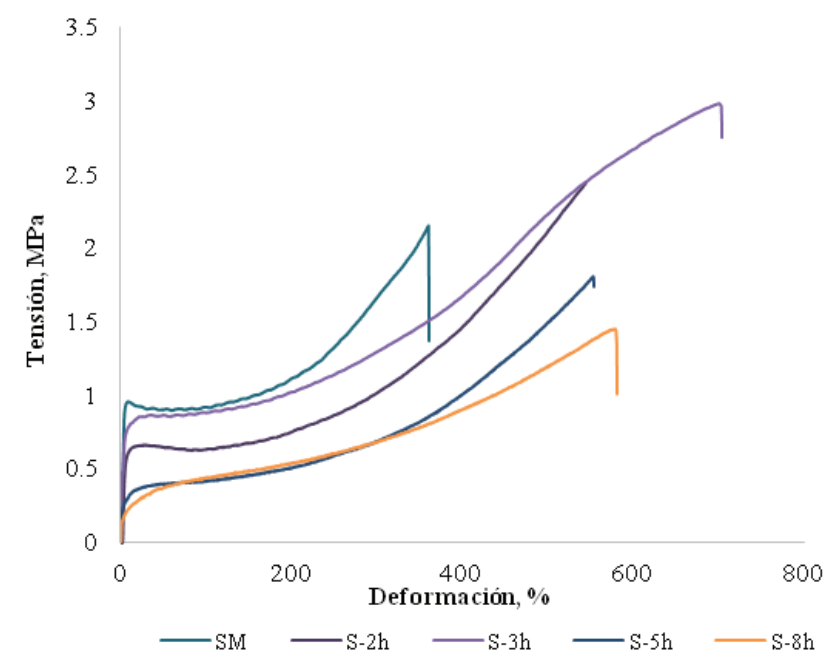

Figura 3. Efecto de la sulfonación en el comportamiento tensión vs deformación. SM: membrana sin modificar, S-: membrana sulfonada al tiempo indicado 


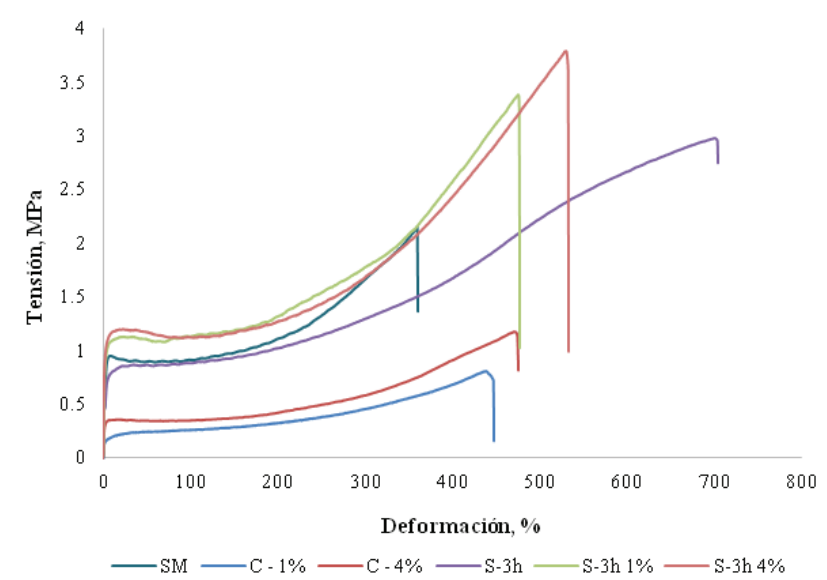

Figura 4. Efecto de la carga inorgánica en el comportamiento tensión vs deformación. SM: membrana sin modificar, S-: membrana sulfonada al tiempo indicado, S- \%: membrana sulfonada al tiempo y carga indicada

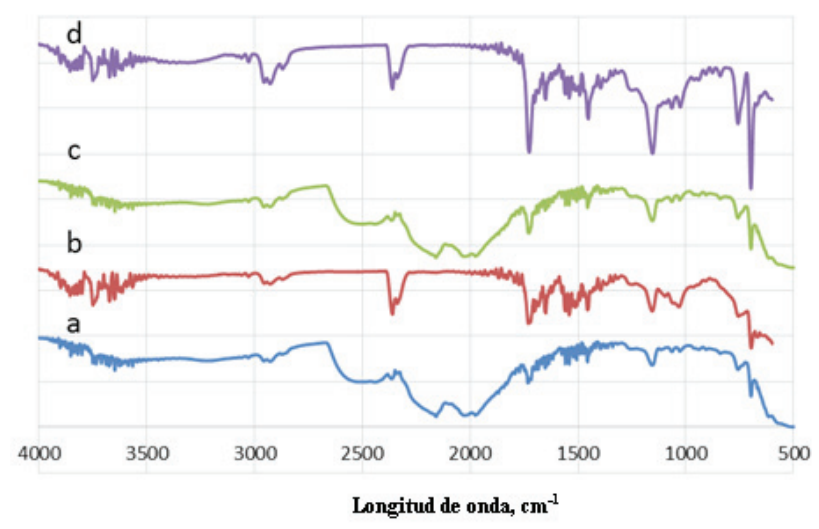

Figura 5. Espectro infrarrojo de las membranas estudiadas: a) membrana sin modificar, b) membrana cargada, c) membrana sulfonada $3 \mathrm{~h}, \mathrm{~d}$ ) membrana sulfonada $8 \mathrm{~h}$

res (Yuan et al., 2014), prepararon membranas de intercambio protónico a partir de polibenzimidazol dopadas con ácido, las cuales redujeron sus propiedades mecánicas al incrementar la carga de ácido de $81 \mathrm{MPa}$ a 4.4 Mpa, sin embargo, funcionaron sin ningún inconveniente en una celda de combustible. Por lo anterior, las membranas obtenidas a partir de estireno-éster acrílico mediante reacciones de sulfonación y adición de nanopartículas de $\mathrm{TiO}_{2}$ como carga inorgánica, tienen alto potencial para su uso en celdas de combustible sin presentar inconvenientes mecánicos durante su operación.

\section{Espectroscopía infrarroja}

La estructura química de los compuestos se investigó mediante FTIR. En la figura 5 se comparan los espectros de las diferentes muestras en el rango de $500-4000 \mathrm{~cm}^{-1}$.
El espectro FTIR de las muestras presenta picos característicos del copolímero que lo conforma. Alrededor de la banda de $1720 \mathrm{~cm}^{-1}$ se encuentra el estiramiento de los grupos carbonilos (=C-O), $1620 \mathrm{~cm}^{-1}$ la presencia de agua dentro de la molécula que caracteriza la resina empleada, $1550 \mathrm{~cm}^{-1}$ a $1600 \mathrm{~cm}^{-1}$ los picos propios de los dobles enlaces entre carbonos $(\mathrm{C}=\mathrm{C})$ presentes en los anillos aromáticos, 1400 y $1050 \mathrm{~cm}-1$ se atribuyen a las vibraciones de estiramiento y deformación de los enlaces sencillos carbono y oxigeno (C-O) (Jiang et al., 2013). En adición se observaron vibraciones en las longitudes de onda de 759 y $697 \mathrm{~cm}^{-1}$, las cuales pueden asociarse al grupo benceno presente en las unidades de estireno del copolímero, donde la vibración a $759 \mathrm{~cm}^{-1}$ puede atribuirse a la mono sustitución del benceno y la banda en $697 \mathrm{~cm}^{-1}$ puede deberse a la deformación del anillo bencénico fuera del plano (Méndez y Toscano, 2013).

Al contrastar los diferentes espectros para cada una de las muestras de membranas sulfonadas se observaron bandas de absorción a $1125 \mathrm{~cm}^{-1}$ y $1200 \mathrm{~cm}^{-1}$ que se asignan a los picos de vibración simétrica y asimétrica de los grupos sulfónicos presentes en la estructura del polímero modificado (Li et al., 2014), donde es más significativa para la membrana sulfonada por un período de tiempo de 8 h. Por otra parte, La absorbancia débil a $1355 \mathrm{~cm}^{-1}$ también se asigna a la tensión asimétrica de grupos de ácido sulfónico (Won et al., 2012) lo cual confirma la presencia de los grupos $-\mathrm{SO}_{3} \mathrm{H}$ dentro de las membranas sulfonadas.

En el caso de las muestras con adición de nanopartículas de $\mathrm{TiO}_{2}$ como carga inorgánica no exhibieron un pico característico alrededor de las bandas de los 550$450 \mathrm{~cm}^{-1}$ (Hernández et al., 2008). Lo anterior probablemente fue producto de la dispersión del material dentro de la matriz polimérica como un relleno, alojándose en la superficie del mismo sin tener ningún tipo de interacción química (Cabrera et al., 2007).

\section{Conclusiones}

Se realizó la caracterización de las propiedades fisicoquímicas de las membranas de intercambio protónico, sintetizada a partir del copolímero de estireno-éster acrílico. El incremento del tiempo sulfonación y la adición de carga incrementan la capacidad de retención de agua de las membranas, debido a la inserción de la carga inorgánica y a los grupos sulfónicos dentro de la estructura, que al poseer propiedades hidrófilas facilitan la captación de agua. Por el contrario, la interacción sulfonación-carga de las membranas reduce parcialmente la retención de agua producto del confinamiento 
de las nanopartículas de $\mathrm{TiO}_{2}$, que reducen el volumen libre. De igual forma, las modificaciones realizadas a las membranas (tiempo de sulfonación, adición de carga y sulfonación-carga) aumentan la capacidad de intercambio iónico de las membranas respecto a la membrana sin modificar, lo cual es consecuencia del incremento de los grupos activos para la transferencia de protones producto de la adición de los grupos sulfónicos y carga de $\mathrm{TiO}_{2}$.

Las propiedades mecánicas de tensión-deformación de la membrana incrementaron con el aumento del tiempo de sulfonación y adición de carga como consecuencia de las interacciones químicas entre los grupos sulfónicos y las nanopartículas de $\mathrm{TiO}_{2}$ con los enlaces del copolímero, lo cual le produce mayor rigidez. Asimismo, a tiempos de sulfonación muy altos se reduce drásticamente su resistencia por la alta adsorción de agua que actúa como plastificante dentro de la matriz polimérica. Los resultados anteriores indican que las membranas preparadas con el copolímero estireno-éster acrílico tienen un alto potencial para aplicaciones como electrolito de intercambio de protones en celdas de combustible.

\section{Agradecimientos}

Los autores agradecen al Departamento de Ciencia, Tecnología e Innovación de Colombia (Colciencias) por el financiamiento del proyecto, bajo el programa Jóvenes Investigadores e Innovadores 2012-2013. Asimismo, un agradecimiento especial a la ingeniera Ana Milena Reyes-Ramos por su colaboración en la síntesis de las nanopartículas de $\mathrm{TiO}_{2}$.

\section{Referencias}

Bose S., Kuila T., Nguyen T.X., Kim N.H., Lau K.T., Hee J. Polymer membranes for high temperature proton exchange membrane fuel cell: Recent advances and challenges. Membrane Science, volumen 36, (número 6), 2011: 813-843.

Cabrera J., Paredes C., Urday E., Santiago J. Preparación y caracterización de películas de alcohol polivinílco conteniendo nanopartículas de $\mathrm{TiO}_{2}$. Revista Iberoamericana de Polímeros, volumen 8 (número 4), 2007: 323 - 332.

Chen B. et al. Proton conductivity and fuel cell performance of organic e inorganic hybrid membrane based on poly (methyl methacrylate)/silica. Hydrogen Energy, volumen 38, 2013 7913-7923.

Cozzi D., De Bonis C., D’Epifanio A., Mecheri B., Tavares A.C., Licoccia S. Organically functionalized titanium oxide/Nafion composite proton exchange membranes for fuel cells applications. Powder Sources, volumen 248, 2014: 1127-1132.
Dai H., Zhang H., Luo Q., Zhang Y., Bi C. Properties and fuel cell performance of proton exchange membranes prepared from disulfonated poly (sulfide sulfone). Powder Sources, volumen 185 (número 1), 2008: 19-25.

Devrim Y., Ercan S., Bac N., Eroglu I. Preparation and characterization of sulfonated polysulfone/titanium dioxide composite membranes for proton exchange membrane fuel cells. Hydrogen Energy, volumen 34 (número 8), 2009: 3467-3475.

Hernández J.M., Garcia L.A., Zeifert B.H., Garcia R., Zermeño B.B., Del Angel T., Cueto A. Síntesis y caracterización de nanopartículas de $\mathrm{N}-\mathrm{TiO}_{2}$-Anatasa. Superficies y vacío, volumen 24 (número 4), 2008: 1-5.

Jetsrisuparb K., Ben-Youcef H., Wokaun A., Gubler L. Radiation grafted membranes for fuel cells containing styrene sulfonic acid and nitrile comonomers. Membrane Science, volumen 450, 2013: 28-37.

Jiang R., Fuller T., Brawn S., Gittleman C. Perfluorocyclobutane and poly (vinylidene fluoride) blend membranesfor fuel cells. Electrochimica Acta, volumen, 110, 2013: 306-315.

Jiang Z., Zhao X., Manthiram A. Sulfonated poly (ether ether ketone) membranes with sulfonated graphene oxide fillers for direct methanol fuel cells. Hydrogen Energy, volumen 38 (número 14), 2013: 5875-5884.

Kim B.N., Lee D.H., Han D.H. Thermal, mechanical and electrical properties on the styrene-grafted and subsequently sulfonated FEP film induced by electron beam. Polymer Degradation and Stability, volumen 93 (número 6), 2008: 14-21.

Kim D.J., Lee H.J., Nam S.Y. Sulfonated poly (arylene ether sulfone) membranes blended with hydrophobic polymers for direct methanol fuel cell applications. Hydrogen Energy, volumen 30 (número 30), 2013: 1-9.

Li J., Wang J., Chen X., Lv Z., Chen T., Wang T. A highly conductive proton exchange membrane for high temperature fuel cells based on poly (5-vinyl tetrazole) and sulfonated polystyrene. Solid State Ionics, volumen 255, 2014: 128-134.

Liao H., Zhang K., Xiao G., Yan D. High performance sulfonated poly (phthalazinone ether phosphine oxides) for proton exchange membranes. Membrane Science, volumen 447, 2013: 4349 .

Lin H.L., Wang S.H. Nafion/poly (vinylalcohol) nano-fiber composite and Nafion/poly (vinylalcohol) blend membranes for direct methanol fuel cells. Membrane Science, volumen 452, 2013: 253-262.

Méndez N.P., Toscano E.A. Evaluación de una membrana de intercambio protónico obtenida a partir de copolímero de éster acrílico y estireno para su aplicación en una celda de combustible, tesis (pregrado ingeniería química), Colombia, Universidad de Cartagena, 2013.

Mohammadi G.H., Jahanshahi M., Rahimpour A. Fabrication and evaluation of Nafion nanocomposite membrane based on $\mathrm{ZrO}_{2}-\mathrm{TiO}_{2}$ binary nanoparticles as fuel cell MEA. Hydrogen Energy, volumen 38 (número 22), 2012: 9387-9394. 
Park J.Y., Kim T.H., Kim H.J, Choi J.H., Hong Y.T. Crosslinked sulfonated poly (arylene ether sulfone) membranes for fuel cell application. Hydrogen Energy, volumen 37 (número 3), 2012: 2603-2623.

Realpe A., Romero K., Acevedo M. Síntesis de membranas de intercambio protónico a partir de mezcla de poliéster insaturado y látex natural, para su uso en celdas de combustible. Información Tecnológica, volumen 26 (número 1), 2015: en prensa.

Realpe A., Mendez N., Acevedo M. Proton exchange membrane from the blend of copolymers of vinyl acetate-acrylic ester and styrene-acrylic ester for power generation using fuel cell. International Journal of Engineering and Technology, volumen 6 (número 5), 2014: 2435-2440

Martínez S., Reyes A. Sintesis de nanopartículas magnéticas modificadas con $\mathrm{TiO}_{2}$ para la fotodegradación de fenol en soluciones acuosas, tesis (pregrado ingeniería química), Colombia, Universidad de Cartagena, 2013, p. 83.

Samberan M.F., Hasani M.M., Ghaffarian S.R., Alimadadi A. Investigation of the effects of AMPS-modified nanoclay on fuel cell performance of sulfonated aromatic proton exchange membranes. Hydrogen Energy, volumen 38 (número 32), 2013: 14076- 14084.

Seol J.H., Won J.H., Yoon K.S., Hong Y.T., Lee S.Y. SiO2 ceramic nanoporous substrate-reinforced sulfonated poly (arylene ether sulfone) composite membranes for proton exchange membrane fuel cells. Hydrogen Energy, volumen 37 (número 7), 2012: 6189-6198.

Shahi V. Highly charged proton-exchange membrane: Sulfonated poly (ether sulfone) silica polyelectrolyte composite membranes for fuel cells. Solid State Ionics, volumen 177 (número 3940), 2007: 3395-3404.

Suryani-Chang Y.N., Lai J.Y., Liu Y.L. Polybenzimidazole (PBI)functionalized silica nanoparticles modified PBI nanocomposite membranes for proton exchange membranes fuel cells. Membrane Science, volumen 403-404, 2012: 1-7.

Treekamol Y., Schieda M., Robitaille L., Mackinnon S., Mokrini A., Shi Z. et al. Nafion®/ODF-silica composite membranes for medium temperatura proton exchange membrane fuel cells. Powder Sources, volumen 246, 2014: 950-959.
Tsai L.D., Chien H.C., Wang C.H., Lai C.M., Lin J.N., Zhu C.Y., Chang C.F. Poly (ethylene glycol) modified activated carbon for high performance proton exchange membrane fuel cells. Hydrogen Energy, volumen 38 (número 26), 2013: 11331-11339.

Wang J., Jiang S., Zhang H., Lv W., Yang X., Jiang Z. Enhancing proton conduction and methanol barrier performance of sulfonated poly (ether ether ketone) membrane by incorporated polymer carboxylic acid spheres. Membrane Science, volumen 364 (número 1-2), 2010: 253-262.

Wang L., Advani S.G., Prasad A.K. PBI/Nafion/ $/ \mathrm{SiO}_{2}$ hybrid membrane for high-temperature low-humidity fuel cell applications. Electrochimica Acta, volumen 105, 2013: 530-534.

Wang Z., Tang H., Zhang H., Lei M., Chen R, Xiao P. et al. Synthesis of Nafion $/ \mathrm{CeO}_{2}$ hybrid for chemically durable proton exchange membrane of fuel cell. Membrane Science, volumen 421-422, 2012: 201-210.

Won J.H., Lee H.J., Yoon K.S., Hong Y.T., Lee S.Y. Sulfonated SBA15 mesoporous silica-incorporated sulfonated poly (phenylsulfone) composite membranes for low-humidity proton exchange membrane fuel cells: Anomalous behavior of humidity-dependent proton conductivity. Hydrogen Energy, volumen 37, 2012: 9202-9211.

Yu D.M., Yoon S., Kim T.H., Lee J.Y., Lee J. Properties of sulfonated poly (arylene ether sulfone)/electrospun nonwoven polyacrylonitrile composite membrane for proton exchange membrane fuel cells. Membrane Science, volumen 446, 2013: 212-219.

Yuan S., Guo X., Aili D., Pan C., Li Q., Fang J. Poly (imide benzimidazoles) for high temperature polymer electrolyte membrane fuel cells. Membrane Science, volumen 454, 2014: 351-358.

Zhao Y., Yin J. Synthesis and evaluation of all-block-sulfonated copolymers as proton exchange membranes for fuel cell application. Membrane Science, volumen 351 (números 1-2), 2012: 28-35.

Zhang L., Chae S. R., Hendren Z., Park J.S., Wiesner M.R. Recent advances in proton exchange membranes for fuel cell applications. Chemical Engineering Journal, volumen 204-206, 2012: 87-97. 


\section{Semblanzas de los autores}

Álvaro Realpe-Jiménez. Director y docente asistente del programa de ingeniería química de la Universidad de Cartagena, Cartagena, Colombia. Ingeniero químico por la Universidad del Atlántico, Barranquilla, Colombia, 1998. En 2002 obtuvo el grado de M.Sc en ingeniería química por la Universidad de Puerto Rico. En 2007 obtuvo el grado de Ph.D. en ingeniería química por la Universidad de Puerto Rico. Sus áreas de investigación incluyen membranas poliméricas para celdas de combustible, energías renovables, modelación de procesos industriales y tecnología de partículas.

Yilmar Maza-Puerta. Ingeniero químico por la Universidad de Cartagena, Colombia. Recibió beca como Joven Investigador del Departamento Administrativo de Ciencia, Tecnología e Innovación de Colombia (Colciencias). Su área de interés se orienta a la preparación de membrana polimérica para aplicación en celda de combustible.

María Teresa Acevedo-Morantes. Docente asistente del programa de ingeniería química de la Universidad de Cartagena, Colombia. Ingeniera química por la Universidad Industrial de Santander, Bucaramanga, Colombia, en 1999. En 2005 obtuvo su M.Sc. como ingeniera química en la Universidad de Puerto Rico. Sus áreas de investigación se orientan a membranas poliméricas para procesos electrolíticos, separación de dióxido de carbono y celdas de combustible. Además, ha desarrollado otras investigaciones con aplicaciones médicas como encapsulamiento de drogas médicas y síntesis de polianhídridos para tratamiento de cáncer.

Adriana Herrera-Barros. Docente asistente del programa de ingeniería química de la Universidad de Cartagena, Colombia. Ingeniera química por la Universidad Industrial del Atlántico, Barranquilla, Colombia, en 2001. En 2005 obtuvo el grado de M.Sc en ingeniería química por la Universidad de Puerto Rico. En 2009 recibió el grado de Ph.D. en ingeniería química por la Universidad de Puerto Rico. Es investigadora postdoctoral del instituto de nanomateriales funcionales de la universidad de Puerto Rico. Sus proyectos de investigación se enfocan en el uso de nanotecnología para aplicaciones biomédicas, biológicas y remediación ambiental. 